Military Technical College Kobry El-Kobbah, Cairo, Egypt



$9^{\text {th }}$ International Conference on Civil and Architecture Engineering ICCAE-9-2012

\title{
LABORATORY EVALUATION OF HOT ASPHALT MIXES FOR AIRFIELD PAVEMENTS IN EGYPT
}

\author{
A. El-Desouky*
}

\begin{abstract}
The main purpose of road or runway pavement is to carry traffic loads conveniently, economically, and safely during its design life. Pavement safety is usually evaluated through several components; among them the skid resistance is one of the most important indica tors. It may cause a serious safety hazard in specific situations especially when water exists in any form. If rutting exists, the risk may increase significantly. As many agencies, owners and operators have recently reported problems related to the poor f rictional properties of newly constructed hot mix asphalt concrete (HMAC) mixes, extensive research work has been carried out to enhance friction of asphalt pavement surfaces. For airfield pavements, friction characteristics are extremely important. It provides the spin-up of the wheels, which is required to operate the electronically controlled antiskid braking systems installed in most modern aircraft. In other words, adequate runway surface friction is essential to braking and deceleration operations. Previous studies emphasized the role of skid resistance to reduce the accident rates. The main objective of this paper was to increase safety on Egyptian airfield pavements through the enhancement of friction characteristics without compromising the other pr operties of asphalt surface mixes. To achieve that, several asphalt mixes utilized in Egypt were prepared and tested for their friction and basic properties. The work conducted in this paper provide important guidelines for selection of the proper hot asph alt mixes when water is expected to exist in any form on runway/road surface.
\end{abstract}

Keywords: Airfield Pavement, Surface friction, Marshall Stability and Aggregate Gradation.

\section{INTRODUCTION AND BACKGROUND}

The main purpose of road and/or airfield pavements is to carry traffic loads conveniently, economically, and safely during its design life [1]. Pavement safety is usually evaluated through several components including; skid resistance, rutting susceptibility, pavement surface light reflectivity, area demarcation, and Debris of foreign objects.

* Assoc. Prof., Dept. of Civil Engineering, Military Technical College, Cairo, Egypt. 
Among these components, pavement slipperiness in terms of skid resistance is the most important component to measure the pavement safety. The lack of skid resistance can provide a serious safety hazard in specific situations, where water exists in any form [2]. On the other hand, surface deformations of asphalt surfaces such as rutting have been observed and reported since the late 1950 's. It was found that rutting of flexible pavements is a common distress type [3]. Flintsch et al. (2003) suggested that water ponds on the road surface due to rutting could cause deficiency in frictional characteristics of pavement surfaces [1]. Federal aviation Administration, FAA concluded similar finding [4]. It was found that pavement structural failure, such as rutting or raveling, is a contributing factor to airfield friction losses. Existence of rutting can restrict the use of pavement and cause serious safety problems when exceeds a certain limit [5]. If the amount of water on the pavement surface exceeds the combined drainage capacity of the tire tread and pavement macrotexture, dynamic hydroplaning occurs. In such case, the channelization or depression caused by the effect of the wheels can represent a serious problem. Sufficient inertial forces exist and separate the tires from the pavement surface [6]. Rutting and exceeded deformations allow puddles to form and consequently increase the hazar $\mathrm{d}$ of skidding.

Several airport agencies, owners and operators have recently reported problems related to the poor frictional properties of newly constructed hot -mix asphalt concrete (HMAC) mixes. The key for improving the air traffic operations and optimi zing the use of runways is to improve skid resistance of asphalt surfaces without compromising the main mix properties. Since the lack of adequate friction is a safety concern, there is a need to review the current Egyptian HMAC specifications for Airport pavements and update them, if necessary. The main objective of this paper was to evaluate airfield hot asphalt mixes in Egypt based on their frictional, physical and mechanical properties and to provide guidelines for the design of improved airfield mixes with higher quality both in terms of safety and performance.

\section{ROLE OF SKID RESISTA NCE TO CONTROL TRAFF IC ACCIDENTS}

For highway pavements, previous study concluded that there is a good correlation between skid resistance and accident rates [7]. Skid resistance provides the needed friction between tires and pavement surface to control vehicle direction and speed. It was found that on wet pavements, skidding problems were the reasons or at least factors of more than a quarter of roads accidents in the United Kingdom [8]. Andrey et al. (2003) has studied the effect of winter precipitation events on accident rate in Ottawa, Ontario, Canada. He concluded that the collision risk have increased significantly during winter season [9]. Panagouli and Kokkalis (1998) found that, for constant traffic volume, the accident rate decreases significantly as the skid number increases [10]. Hosking (1987) found that an enhancement of $10 \%$ in the level of skid resistance resulted in 13 $\%$ reduction in the wet accident rate [11]. Other studies indicated that the microtexture and macrotexture have a substantial influence on accident rate especially at high speeds on wet pavements. As a general conclusion they found that "wet weather accident rates are a little bit more than twice those of dry pavement accidents" [12]. Chelliah et al. (2003) have developed a relationship between the number of wet accidents and the friction of pavement surface. The model was developed using all wet accident data for U .S. highways occurring in 2001 [13].

For airfield pavements, friction characteristics are extremely important. It provides the spin-up of the wheels, which is required to operate the electronically controlled antiskid braking 
systems installed in most modern aircraft. In other words, adequ ate runway surface friction is essential to braking and deceleration operations. The national transportation safety board reported that "runway conditions were a cause or factor in 115 aircraft accidents between 1983 and 1987" [14]. Contaminated runway surface, by snow and/or ice, was also a factor in approximately 30 aircraft accidents between 1983 and 1995. Additionally, inaccurate data on runway friction conditions was a reason for many dangerous aircraft operations [15]. At Los Angles International Airport, a jumbo jet DC-10 was completely loss due to lack of skid resistance of runway surface in 1970s. The touch down zone was very slippery at the time of accident [16]. Because of inaccurate runway friction information, a fatal aircraft accident occurred in Dryden, Ontario, Canada, in 1989 [17]. Another aircraft accident occurred at a Mexican airport due to insufficient data on runway friction. The DC -9 aircraft was thoroughly damaged during a thunderstorm and 4 passengers were killed [18]. In 1991, "Although the weather conditions were good, a brand new British aircraft skidded more than 1,000 m into the Beagle channel, Chili, during landing. Among 60 tourists on board, 20 people died". An investigation was conducted to figure out why the aircraft skidded. It was found that the skid resistance of runway surface was low and the accident took place due to viscous hydroplaning [14]. In 2007, Airbus A320-233 operated by TAM Airlines continued off the end of the runway due to skidding as shown in Figure (1). The aircraft exploded on impact with a four-story TAM Express facility, resulting in a large fire and killing everybody on board instantly. 199 people were killed including 12 on ground. The accident report points several factors that may have contributed to the accident, as a high volume of rain on the day, with the formation of puddles on the runway, as well as the absence of grooving [19].

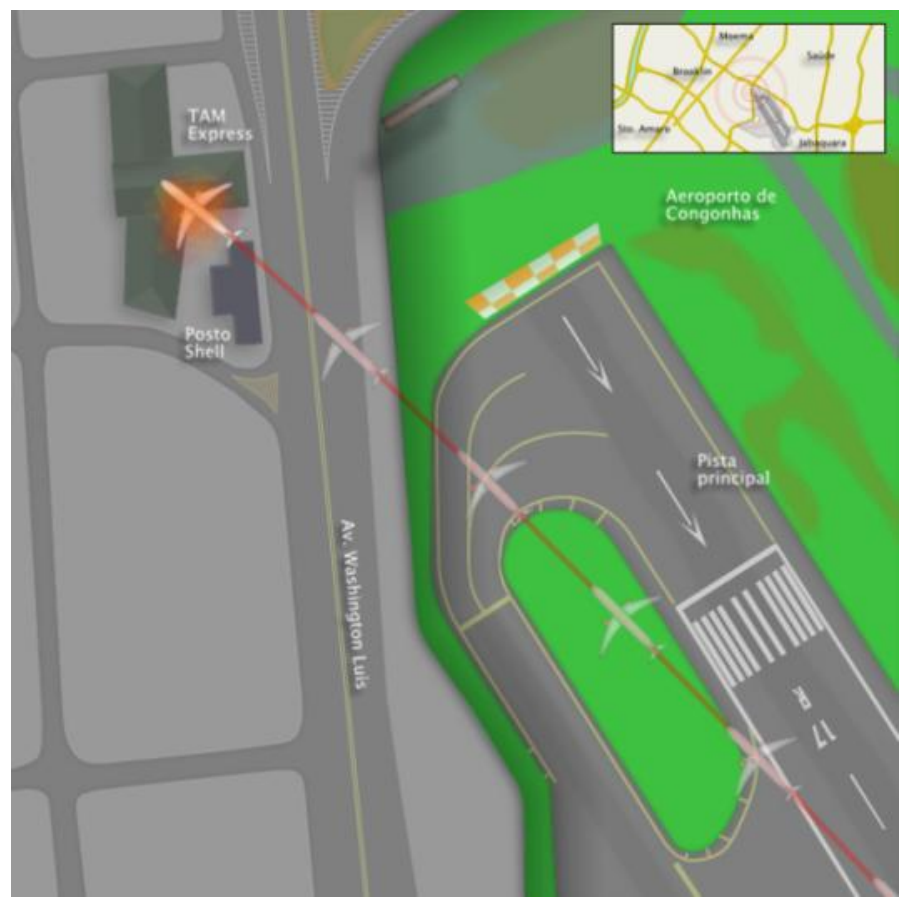

Figure (1): Path of the aircraft after skidding, São Paulo, Brazil [19]. 


\section{TESTING PROGRAM}

\section{Mix Design and Preparation}

Five different job mix design formulas were obtained from the General Authority of Roads \& Bridges and Land Transport, Egypt. The aggregate samples were prepared and graded by sieve analysis according to ASTM (1996) [20]. Aggregates for mix 1 to mix 4 (surface courses) and for mix 5 (base course) were blended according to pre-specified aggregate percentages. For mix 6 to Mix 11, prepared at laboratory, many trials were performed to blend the aggregates in one gradation that fit in the Egyptian Standards [21]. Based on these trials, four aggregate gradations were chosen for the mix design stage. These four aggregate gradations were referred to Grad 1 to Grad4, respectively. Aggregate gradations were used to prepare six different asphalt mixes as follows;

Marshall mix design procedures were used in this phase of study. Aggregates were combined and placed in the oven for four hours to attain the mixing temperature. Binder was placed in the oven and heated to a temperature that would reach the proper viscosity $\left(165^{\circ} \mathrm{C}\right)$. The mixing bowl was also heated to the same temperature to prevent temperature loss during the blending process. Then the binder was added to the hot aggregates according to the selected AC, in percent of total mass, of the mix. The Asphalt cement used was 60/70 asphalt of specific gravity 1.02 . The mixing temperature was $165^{\circ} \mathrm{C}$. After that the mixture was mixed until the binder completely and uniformly coated all aggregate particles. About three kilograms from each mix was kept in its loose condition to be tested for its Maximum density (MD). Preheated moulds of 4 inches in diameter were used to make the core samples. Two filter paper were used during compaction to avoid sample sticking to the mould and compactor hammer and to get smooth sample surface. The specimens were compacted with 50 blows on each side. The compaction temperature was $140^{\circ} \mathrm{C}$. Once the compaction was completed, the filter papers were removed and the specimens were cooled in room temperature for 24 hours. Specimens were then extracted from moulds and dimensions were measured. The specimens were tested for their (bulk density) BD, and MD, Marshall stability and flow. Air voids (Av) and voids in mineral aggregates (VMA) were calculated and the optimum AC was determined for each aggregate gradation. The optimum asphalt contents (AC) of Grad1 and Grad2 were determined to prepare Mix 6 and Mix7, respectively. Figure (2) illustrates the aggregate size distribution for all aggregate gradations used in this study. The figure shows that Mix 5 had the coarsest aggregate gradation and Mix 6 had the finest aggregate gradation as indicated by the percentage passing a given sieve. The optimum AC values were determined to be $4.5 \%$ and $5 \%$ for Mix6 and Mix 7, respectively. To study the effect of AC on the performance of HAM, tow different AC were used with Grad 2 to prepare Mix 8 (4.5\%) and Mix9 (6\%), respectively. Mix 10 and Mix11 were prepared using Grad3 and Grad4 with the same optimum AC of Grad $2(5 \%)$ to study the effect of aggregate gradation on the properties of HMA. Table (1) presents the basic properties for the seven mixes prepared in this study.

\section{Preparation of Friction Test Specimens}

For each mix under study, a slab of dimensions $70 \times 25 \times 7.5 \mathrm{~cm}$ was prepared and 
compacted using the plate compactor as shown in Figure (3). A ramp was prepared at the end of the wooden form to allow the compactor to move back and forth on top of asphalt slabs without damaging the wooden edges of the forms. For each wooden form an asphalt layer of approximately $85 \mathrm{~mm}$ was laid on top of the wooden base and leveled off manually. The compaction was completed after 10 passes per slab. The slabs were labeled from S1 to S11 and were tested for their frictional properties using the British Pendulum Tester (BPT), [22]. After testing for their frictional properties, three cores were extracted from each slab to check that the slab had a homogenous density.

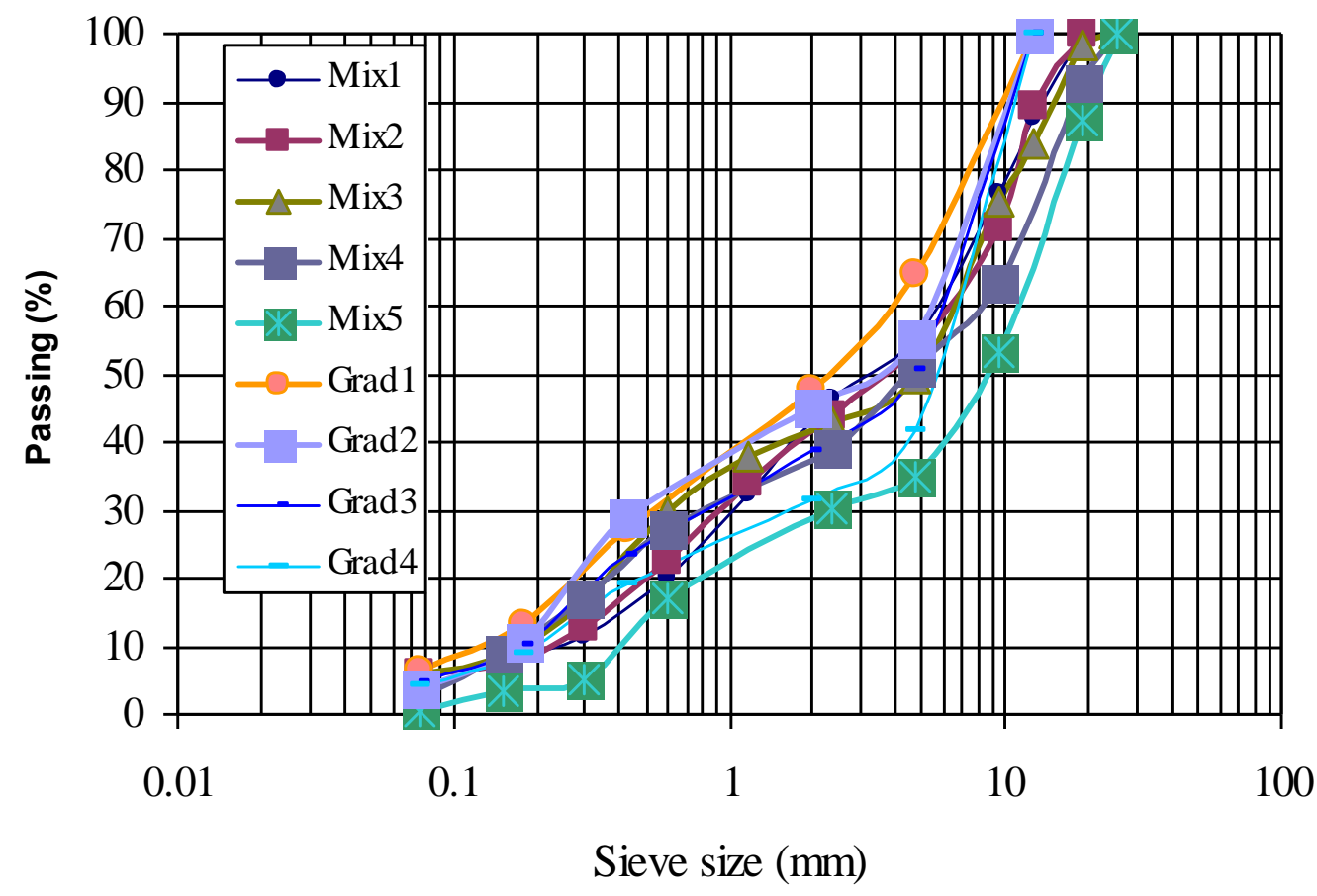

Figure (2): Gradations of different used aggregates.

Table (1): Results of Marshall mix design process.

\begin{tabular}{|c|c|c|c|c|c|c|}
\hline Mix & $\begin{array}{c}\text { Stability } \\
(\mathrm{lb})\end{array}$ & $\begin{array}{c}\text { Density } \\
\left(\mathrm{kg} / \mathrm{cm}^{2}\right)\end{array}$ & $\begin{array}{c}\text { Air voids } \\
(\%)\end{array}$ & $\begin{array}{c}\text { Flow } \\
(1 / 100 ")\end{array}$ & $\begin{array}{c}\text { VMA } \\
(\%)\end{array}$ & $\begin{array}{c}\text { AC } \\
(\%)\end{array}$ \\
\hline Mix1 & 3020 & 2.393 & 3.6 & 10.8 & 15.7 & 5.5 \\
\hline Mix2 & 2370 & 2.394 & 3.5 & 11.4 & 15.85 & 5.45 \\
\hline Mix3 & 2510 & 2.331 & 3.6 & 11.8 & 15.3 & 5.5 \\
\hline Mix4 & 1990 & 2.301 & 4.8 & 11.9 & 15.2 & 4.8 \\
\hline Mix5 & 1830 & 2.285 & 4.7 & 11.3 & 15.1 & 4.0 \\
\hline Mix6 & 2795 & 2.285 & 3.99 & 11.5 & 20.42 & 4.5 \\
\hline Mix7 & 2810 & 2.303 & 3.21 & 8.0 & 19.93 & 5.0 \\
\hline
\end{tabular}




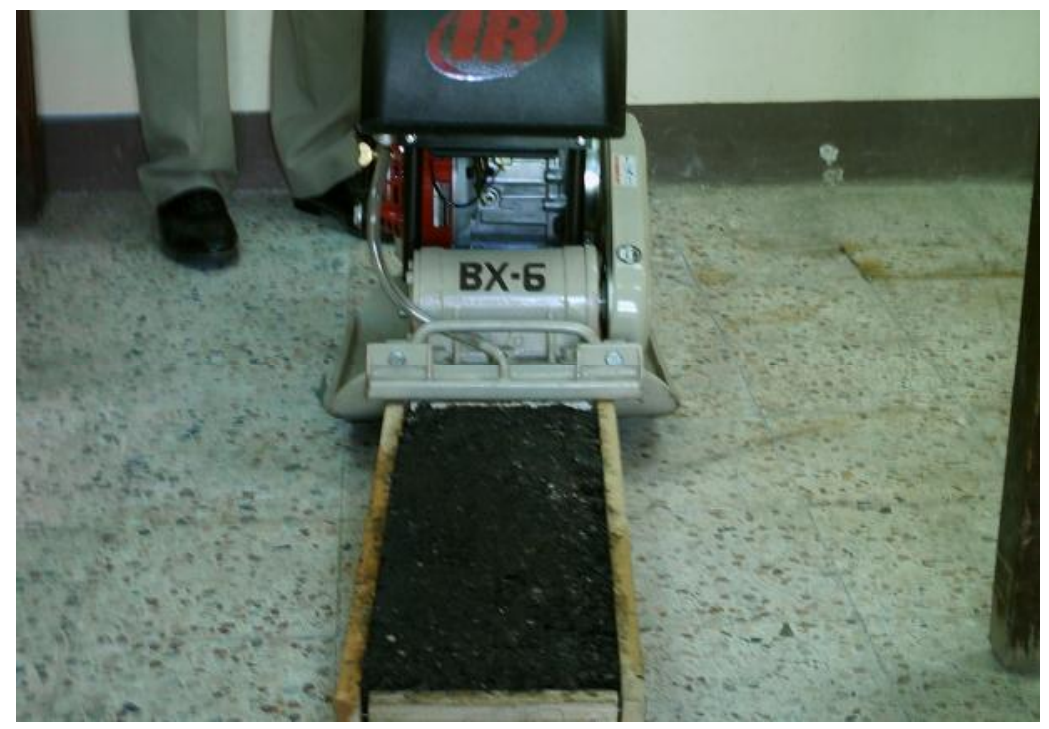

Figure (3): Compaction process of slab specimens.

\section{RESULTS AND ANALYSIS OF THE TESTING PROGRAM Friction test results}

Frictional properties of asphalt mixes were measured using the BPT [22] as shown in Figure (4). Instrument was leveled using the leveling screws until the bubble was centered in the sprit level. After leveling, the pendu lum was adjusted such that its free swing carried pointer to zero. Zero-adjustment was performed by raising the pendulum mechanism to allow slider to swing free of test surface. Locking knob was then tightened and the pendulum was placed in release position. Pendulum was released and pointer reading was noted. Adjustment procedures were repeated until the pendulum free swing carried pointer to zero. With pendulum hanging free, pendulum was lowered such that the edge of slider just touched the pavement surfa ce. Contact path length was adjusted using a marked ruler provided with the pendulum. Enough water was applied to cover the test area completely. One swing was executed but the reading was not recorded. After that four more swings were carried out with the surface rewetted each time and results were recorded. For each slab, five different locations were marked to be tested. These locations were labeled form L1 to L5. The friction test was performed in the direction of compaction at all locations. The friction was measured four times at each location and the results were recorded as R 1 to R4. The average British pendulum number (BPN) was calculated at each location and the mean BPN for each mix was determined. 


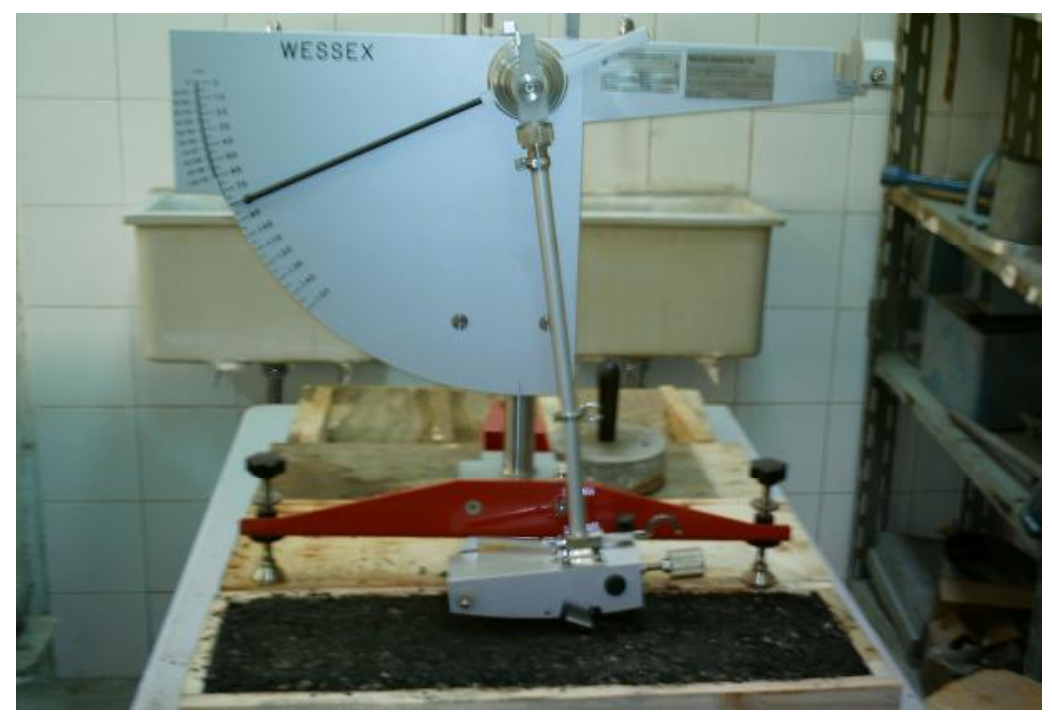

Figure (4): Friction test using BPT.

The mean BPN values vary from a minimum of 55 (Mix 6 of finest aggregate gradation) to a maximum of 80 (Mix5 of coarser aggregate gradation). Table (2) summarizes the results of friction test as well as Marshall stability for all mixes. In general, the friction val ues increased as the aggregate gradation got coarser. To investigate that clearly, friction test results of Mix 7, Mix 10 and Mix 11 were plotted on Figure (5) as indicated by the solid bars. These mixes had the same $\mathrm{AC}$ of 5\% and different aggregate gradations; Grad2, Grad3 and Grad4, respectively. The figure shows that the friction values of asphalt surfaces increased for coarser aggregate gradations. In addition, the figure demonstrates the benefit of using the optimum AC to obtain higher values of surface friction where friction test results of Mix 7, Mix 8 and Mix 9 were plotted as the hatched bars. These mixes had the same aggregate gradations (Grad2) and different AC values of 5\%, 4.5\% and 6\%, respectively. The figure shows that the Optimum AC value of 5\% yielded the higher BPN of 66. Lower or higher values of the optimum AC resulted in smaller BPN of 62 .

\section{Marshall Stability test results}

The main purpose for this phase of results analysis is to select a surface layer that may improve the frictional properties without compromising the other mix properties. Marshall stability test results for all mixes are presented in Table (1), the Table shows that Mix 6 of the finest aggregate gradation yielded a stability value of $2795 \mathrm{lb}$, while Mix 5 of the coarsest aggregate gradation yielded a lower value of $1830 \mathrm{lb}$ only. Although Mix 5 (base layer) yielded the highest friction value of 80 in terms of BPN, it can not be used as a surface layer based on its stability value. Similarly, Mix6 (of finest aggregate gradation) had the lowest friction value of 55 and the highest stability value (after Mix1) of $2795 \mathrm{lb}$. Ignoring Mix5, Tables $(1,2)$ shows that Mix 1 had medium aggregate gradation (compared to the base coarse, Mix5) and it resulted in the highest stability and friction values followed by Mix 3 (of medium gradation as a surface course) that gave a high friction value of 75 and a very good stability value of $2510 \mathrm{lb}$. The obtained stability results suggest that using coarser aggregates might improve both the surface friction and stability. 
However, caution should be observed when choosing coarse aggregates (as that used for base courses) that may cause lack of particle to particle contact and consequently reduce the stability.

Table (2): Summary of friction test results (BPN).

\begin{tabular}{cccccccccccc}
\hline Mix No. & $\mathbf{1}$ & $\mathbf{2}$ & $\mathbf{3}$ & $\mathbf{4}$ & $\mathbf{5}$ & $\mathbf{6}$ & $\mathbf{7}$ & $\mathbf{8}$ & $\mathbf{9}$ & $\mathbf{1 0}$ & $\mathbf{1 1}$ \\
\hline Friction & 77 & 65 & 75 & 74 & 80 & 55 & 66 & 62 & 62 & 68 & 70 \\
\hline
\end{tabular}

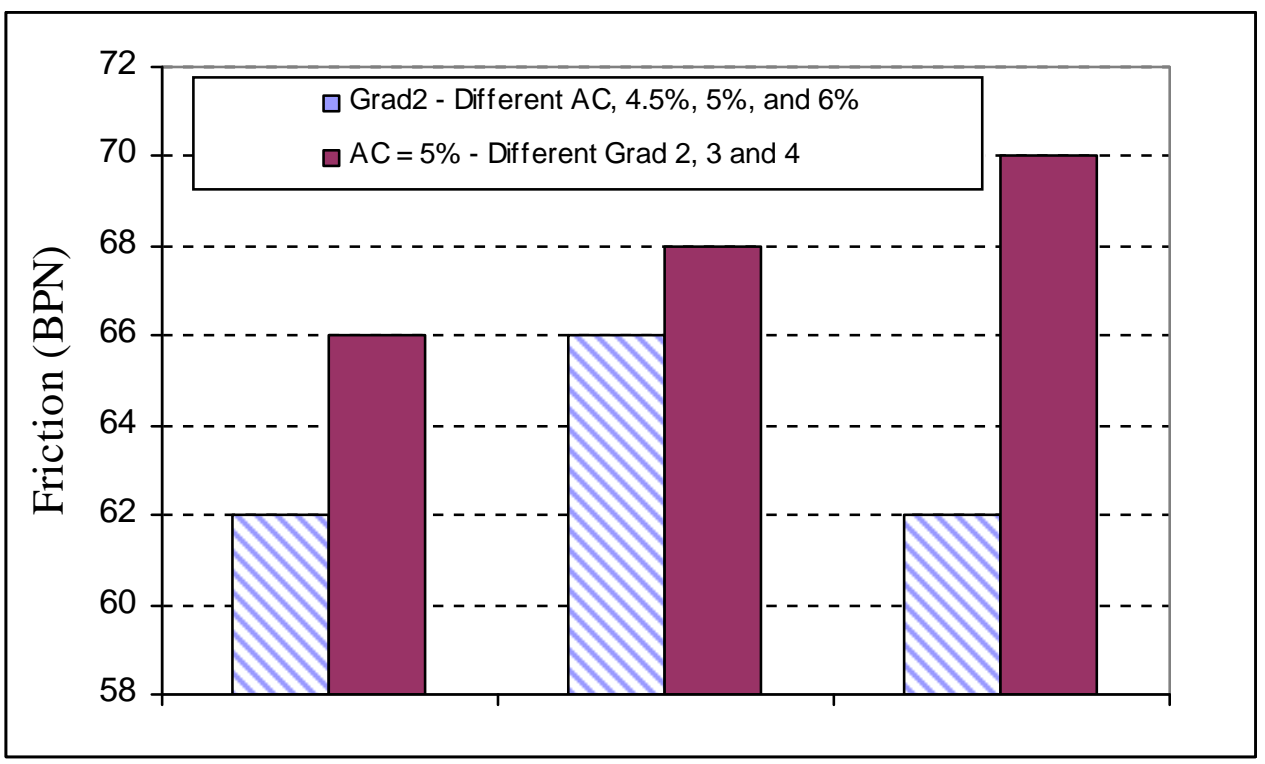

Figure (5): Effect of AC and aggregate gradations on the measured friction values.

\section{CONCLUSIONS}

Based on the results of this study, the following can be concluded:

1. It has been shown that surface friction of airport/road mixes could be quantified in the laboratory utilizing simple measuring device.

2. Using coarser aggregates could improve frictional properties of asphalt pavement surfaces. In most cases, this improvement was accompanied with better stability. However in few cases using coarse aggregate did not enhance the stability.

3. Use of relatively excessive coarse aggregate could enhance frictional properties of asphalt pavements. The analysis indicated the presence of an op timum value after which increasing the proportion of coarse aggregates may actually reduce the desired properties.

4. Using the optimum asphalt content has been shown to be a key factor in obtaining asphalt 
mixes with high surface friction.

5. It is recommended to use the coarsest aggregate gradation of the aggregate band in Egyptian Code of Practice for surface courses when it is expected that surface water may exist on the airfield/road surface in any form.

\section{REFERENCES}

[1] Flintsch, G.W., de Leon, E., McGhee, K.K., and Al-Qadi, I.L., "Pavement Surface Macrotexture Measurement and Application", Transportation Research Board, 2003 Annual Meeting, National Research Council, Washington D.C., 2003.

[2] RTAC, Roads and Transportation Association of Canada, Pavement Managemen $t$ Committee, "Pavement Management Guide," 1977.

[3] Nikolaides, A., "Rutting and Volumetric Properties of SMA Mixtures", Proceedings of the Institution of Civil Engineers-Transport, Vol. 141, No. 3, pp. 135-141, 2000.

[4] FAA, Federal Aviation Administration, "Measurement, Construction, and Maintenance of Skid-Resistant Airport Pavement Surfaces", Advisory Circular, U.S. Department of Transportation, 1997.

[5] Al-Abdul Wahhab, H.I. and Balghonaim, F., "Asphalt Pavement Temperature Related to Arid Saudi Environment”, Journal of Materials in Civil Engineering, Vol. 6, No. 1, pp. 114, 1994.

[6] Browne, A.I., and Whicker, D., "An Interactive Tire-Fluid Model for Dynamic Hydroplaning", In Frictional International of Tire and Pavement, ASTM STP 793 (W.E. Meyer and J.D. Walter, Eds.), American Society for Testing and Materials, Philadelphia, Pa., pp. 130-150, 1993.

[7] Hatherly, L.W. and Young, A.E., “The Location and Treatment of Urban Skidding Hazard Sites", Transportation Research Record, No. 623, Transportation Research Board, National Research Council, Washington, D.C., pp. 21-28, 1976.

[8] Kennedy, C.K., Young, A.E., and Butler, I.C., "Measurement of Skidding Resistance and Surface Texture and the Use of Results in the United Kingdom", In Symposium: Surface Characteristics of Roadways, ASTM, Philadelphia, 1990, pp. 87-102.

[9] Andrey, J., Mills, B., and Vandermolen, J., "A Temporal Analysis of Weather-Related Collision Risk for Ottawa, Canada: 1990-1998”, Transportation Research Board, 2003 Annual Meeting, National Research Council, Washi ngton DC, 2003.

[10] Panagouli, O.K., and Kokkalis, A.G., "Skid Resistance and Fractal Structures of Pavement Surface", CHAOS Solitons and Fractals, Vol. 9, No. 3, pp. 493-505, 1998.

[11] Hosking, J.R., "Relationship between Skidding Resistance and Accident Frequenc y: Estimates Based on Seasonal Variations", TRRL Report RR76, Department of Transport, Crowthorne, UK, 1987.

[12] Wambold, J.C., Henry, J.J., and Hegmon, R.R, "Skid Resistance of Wet Weather Accident Site", In the Tire Pavement Interface, ASTM ATP 929, M.G. Pottinger and T.J. Yager, Eds., American Society for Testing and Materials, Philadelphia, Pa., pp. 47-60, 1986.

[13] Chelliah, T., Stephanos, P., Shah, M.G, and Smith, T., “Developing a Design Policy to Improve Surface Characteristics”, Transportation Research Board, 2003 Annual Meeting, National Research Council, Washington D.C., 2003. 
[14] Thenoux, G., Allen, W., and Bell, C.A., "Study of Aircraft Accident Related to Asphalt Runway Skid Resistance", Transportation Research Record, No. 1536, Transportation Research Board, National Research Council, Washington, D.C., pp. 59-63, 1996.

[15] http://www.hq.nasa.gov/office/aero/library/chicago/runway.htm, October 2000, accessed 04/04/2003.

[16] http://www.asft.se/history.html, 1997, accessed 05/03/2003.

[17] Moshansky, P.J., Commission of Inquiry into the Air Ontario Crash at Dryden, Ontario, Final Report, Ottawa, Ontario, 1992.

[18] Yager, T.J., Wambold, J.C., Henry, J.J., Anderson, A., and Bastain, M., “Joint Winter Runway Program Accomplishments", the Virginia Department of Transportation and Virginia Tech Pavement Evaluation 2002 Conference, October 21-25, Roanoke, Virginia, 2002.

[19] http://en.wikipedia.org/wiki/TAM_Airlines_Flight_3054, accessed 10/3/2012.

[20] ASTM, Designation (C702-93), (C136-95a), (D546-94), and (E303-93 1996), Annual Book of American Society for Testing and Materials ASTM Standards, Section 4, 1996.

[21] Egyptian code of Practice for Urban and Rural Roads, Part 4, 104/4, Materials and Testing, ECP, First Edition, 2008.

[22] Wessex Skid Tester, "Operating Instruction", Version 4.0, Wessex Engineering Limited, 2007. 